PublisherName $\quad$ : Springer International Publishing

PublisherLocation : Cham

PublisherlmprintName : Springer

\title{
Overloaded CDMA Systems with Displaced Binary Signatures
}

\section{Articlel nfo}

\begin{tabular}{|c|c|c|}
\hline ArticlelD & : 1119 & \\
\hline ArticleDOI & : 10.1155/S1687147 & $20440601 X$ \\
\hline ArticleCitationID & : 851514 & \\
\hline ArticleSequenceNumber & $: 16$ & \\
\hline ArticleCategory & : Research Article & \\
\hline ArticleCollection & $\begin{array}{l}\text { : Innovative Signal T } \\
\text { Cellular CDMA Syst }\end{array}$ & $\begin{array}{l}\text { Transmission and Detection Techniques for Next Generation } \\
\text { tems }\end{array}$ \\
\hline ArticleFirstPage & $: 1$ & \\
\hline ArticleLastPage & $: 2$ & \\
\hline \multirow[t]{4}{*}{ ArticleHistory } & : RegistrationDate & : 2003-10-31 \\
\hline & Received & : 2003-10-31 \\
\hline & Revised & : 2004-5-17 \\
\hline & OnlineDate & : 2004-7-29 \\
\hline ArticleCopyright & \multicolumn{2}{|c|}{$\begin{array}{l}\text { Vanhaverbeke and Moeneclaey2004 } \\
\text { This article is published under license to BioMed Central Ltd. This is an open } \\
\text { access article distributed under the Creative Commons Attribution License, } \\
\text { which permits unrestricted use, distribution, and reproduction in any medium, } \\
\text { provided the original work is properly cited. }\end{array}$} \\
\hline ArticleGrants & \multicolumn{2}{|l|}{ : } \\
\hline ArticleContext & \multicolumn{2}{|l|}{ : 136382004200411} \\
\hline
\end{tabular}


Frederik Vanhaverbeke, Aff1

Corresponding Affiliation: Aff1

Email: frederik.vanhaverbeke@telin.ugent.be

Marc Moeneclaey, Aff1

Email: marc.moeneclaey@telin.ugent.be

Aff1 Department of Telecommunications and Information Processing (TELIN), Ghent University, St-Pietersnieuwstraat 41, Ghent 9000, Belgium

\section{Abstract}

We extend three types of overloaded CDMA systems, by displacing in time the binary signature sequences of these systems: (1) random spreading (PN), (2) multiple-OCDMA (MO), and (3) PN/OCDMA (PN/O). For each of these systems, we determine the time shifts that minimize the overall multiuser interference power. The achievable channel load with coded and uncoded data is evaluated for the conventional (without displacement) and improved (with displacement) systems, as well as for systems based on quasi-Welch-bound-equality (QWBE) sequences, by means of several types of turbo detectors. For each system, the best performing turbo detector is selected in order to compare the performance of these systems. It is found that the improved systems substantially outperform their original counterparts. With uncoded data, (improved) PN/O yields the highest acceptable channel load. For coded data, MO allows for the highest acceptable channel load over all considered systems, both for the conventional and the improved systems. In the latter case, channel loads of about $280 \%$ are achievable with a low degradation as compared to a single user system.

\section{Keywords}

oversaturated channels, total squared correlation, CDMA, random spreading, interference cancellation, turbo detection

This PDF file was created after publication. 